\title{
COORDENAÇÃO EFETIVA E SISTEMATIZAÇÃO: NOVAS TENDÊNCIAS DA MELHORA DA QUALIDADE REGULATÓRIA NO BRASIL
}

CARLOS RAGAZZO ${ }^{1-2}$

RESUMO: O presente artigo tem como objetivo argumentar que existem duas novas tendências relacionadas ao movimento de melhora regulatória no Brasil: as tendências de (i) coordenação efetiva e de (ii) sistematização de boas práticas de regulação. Para atingir esse objetivo, como forma de contextualizar a discussão que se pretende levantar, inicialmente, será elaborado um breve histórico das origens da preocupação nacional com o incremento qualitativo das regulações. Em momento posterior, busca-se demonstrar que experiências isoladas (principalmente de agências reguladoras federais) voltadas para melhorar a regulação de certos setores começam a ser, por meio de um efetivo movimento coordenado pela Casa Civil da Presidência da República, sistematizadas em normas e guias orientativos. Nesse ponto, como se argumentará, esses movimentos têm como uma de suas tônicas principais a cíclica necessidade de captação de investimentos estrangeiros. Por fim, se concluirá que os fenômenos ainda se encontram em estágio embrionário e que contam com futuros desafios de incorporação ao sistema regulatório brasileiro.

Palavras-Chave: Melhora regulatória; Coordenação efetiva; Sistematização; Sistema regulatório brasileiro.

\footnotetext{
${ }^{1}$ Professor Doutor da Escola de Direito da Fundação Getúlio Vargas - FGV DIREITO RIO. Membro Permanente do Mestrado em Direito da Regulação da FGV DIREITO RIO. Pós-Doutorando em Economia pela Universidade Federal Fluminense.

$2 \mathrm{O}$ autor faz, aqui, um agradecimento à valorosa contribuição de Mateus Barreto para o desenvolvimento deste artigo. Os erros, naturalmente, ficam por conta do autor, ao passo que os acertos são com ele certamente compartilhados.
} 


\title{
EFFECTIVE COORDINATION AND SYSTEMATIZATION: NEW TRENDS OF REGULATORY QUALITY IMPROVEMENT IN BRAZIL
}

\begin{abstract}
The present article aims to argue that there are two new trends related to the better regulation phenomena in Brazil: the trends of (i) effective coordination and (ii) systematization of good regulatory practices. To reach this objective, as a way of contextualizing the discussion that is intended to be raised, initially, a brief history of the origins of the national concern with the qualitative increase of the regulations will be elaborated. After, it is intended to demonstrate that isolated experiences (mainly from federal regulatory agencies) aimed to improve the regulation of certain sectors begin to be, through an effective movement coordinated by the Civil Cabinet of the Presidency of the Republic, systematized in rules and guidelines. At this point, as will be argued, these movements have as one of their main subjects the cyclical need to attract foreign investment. Finally, it will be concluded that the phenomena are still at an early stage and that they have future incorporation challenges into the Brazilian regulatory system.
\end{abstract}

KEYWORDS: Better regulation; Coordination; Systematization; Brazilian regulatory system. 


\section{INTRODUÇÃO}

Grandes ciclos de reforma na estrutura da administração pública brasileira, geralmente, são impulsionados pela necessidade de atração de investimento estrangeiro. O principal deles, ocorrido na década de $90^{3}$, que delegou à iniciativa privada a prestação de determinados serviços públicos e criou agências fiscalizadoras dessa prestação (as agências reguladoras), teve justamente, a captação de recursos externos como uma das tônicas primordiais (ACCURSO, 2009, p. 267). Naquela época, a diminuição da presença estatal em determinados setores da economia e a criação de entidades responsáveis pela regulação das atividades prestadas por empresas privadas foram os mecanismos escolhidos para lidar com necessidade de aumentar a confiança de investidores e, consequentemente, absorver apoio para grandes projetos de infraestrutura (OCDE, 2008b).

Nessa linha, durante algum tempo, o debate sobre a regulação, no Brasil, esteve focado no desenho da diminuição do tamanho do Estado (i.e., do processo de desregulação) e no desenho institucional de agências reguladoras, de caráter autônomo, independente 4 . O ritmo da desregulação, o grau de autonomia das agências e a legitimidade de suas decisões eram nuances que permeavam a literatura nacional ${ }^{5}$.

Entretanto, novas demandas de ordem econômica e social impuseram a necessidade de se desviar as discussões sobre desenho institucional e desregulação (deregulation) para outras mais preocupadas com a melhora do conteúdo/substância da regulação (better regulation) ${ }^{6}$. Sob o espectro econômico, era preciso regular melhor para, novamente, atrair investimentos estrangeiros e, sob o espectro social, era preciso regular

${ }^{3}$ Para mais detalhes sobre a reforma ocorrida na década de 90 vide Costa (2008).

${ }^{4}$ Nesse sentido, vide, por exemplo, Santos (2009, p. 107) e Ramalho (2009).

${ }^{5}$ Nesse aspecto, como expus em Ragazzo (2011), é possível se identificar "ondas" no processo de desenvolvimento da regulação no Brasil. A primeira onda diz respeito à discussão, na literatura, sobre o grau de autonomia desejável das agências reguladoras em relação aos demais poderes (Legislativo e Judiciário) e em relação ao próprio poder ao qual estavam vinculadas (Executivo). A segunda, diz respeito à necessidade de criação de canais de participação social nas decisões das agências, já que se tratavam de entidades desvinculadas de accountability eleitoral e já que era preciso atribuir algum grau de legitimidade às duas decisões. A terceira onda, atualmente em voga, se trata do debate da melhora regulatória - foco deste artigo e que será mais bem explicada ao longo dele.

${ }^{6}$ Importante deixar claro que os temas da desregulação e melhora regulatória não são incompatíveis entre si. Pelo contrário, é possível que uma medida de melhora regulatória envolva, justamente, a desregulação, como, por exemplo, medidas relacionadas à gestão do estoque regulatório - tema que também serão mais bem tratadas ao longo deste artigo. 


\section{REVISTA ESTUDOS INSTITUCIONAIS}

melhor para obtenção de resultados efetivos (GAETANI; KÉLVIA, 2009). Nesse novo contexto, os custos e benefícios da regulação (mais especificamente, ideias relacionadas à realização de análises prévias do impacto das regulações) ganham a atenção da literatura especializada mais atual, já que tal relação seria fundamental para impulsionar o fenômeno do incremento da qualidade regulatória e, consequentemente, para fazer frente à cíclica demanda por investimentos e às demandas sociais.

Atualmente, as discussões sobre os custos/benefícios das regulações e, consequentemente, sobre melhora regulatória, persistem e, inclusive, ganharam, recentemente, contornos especiais. Nesse aspecto, principalmente, (i) a tramitação do Projeto de Lei Geral das Agências Reguladoras, que incorpora e uniformiza a necessidade de utilização de determinadas ferramentas de melhora regulatória; (ii) a criação, pelo Governo Federal, em novembro de 2017, de uma Política de Governança Pública Federal, que cria um órgão responsável por coordenar as ações voltadas à melhoria regulatória, bem como que tem essa ideia como uma de suas vertentes principais, (iii) o lançamento, em meados deste ano, pelo Governo Federal, das "Diretrizes Gerais e Roteiro Analítico Sugerido Para Análise De Impacto Regulatório" e do "Guia Orientativo Para Elaboração De Análise De Impacto Regulatório" e (iv) a articulação original dessas ações pela Casa Civil da Presidência da República, são movimentos que parecem sugerir a inauguração de duas tendências associadas ao fenômeno da melhora regulatória no Brasil: as vertentes de coordenação efetiva (pela Casa Civil) e sistematização (por meio da edição de normas e de softlaw) das melhores práticas regulatórias para fortalecimento da qualidade do sistema de regulação brasileiro.

Em função do exposto, este artigo argumenta que, de fato, tais fenômenos surgiram e que eles inauguram uma nova fase do debate de melhora regulatória no Brasil. Para elaborar tal argumentação, este texto foi estruturado em quatro partes. Na primeira parte, serão expostas as origens da preocupação nacional com o incremento da qualidade da regulação. Na segunda, serão expostas algumas práticas isoladas de entidades nacionais (principalmente das agências reguladoras federais) voltadas para o incremento da qualidade de suas regulações. Na terceira, serão analisadas evidências de que tais práticas isoladas começam a ser sistematizadas em normas vinculantes e guias orientativos, bem como que tal organização é, fundamentalmente, articulada pela Casa Civil da Presidência da República. Nesse ponto, conforme já adiantado, se evidencia o surgimento das tendências de sistematização e coordenação efetiva das melhores práticas regulatórias, tendo como uma de suas tônicas principais a cíclica necessidade de captação de investimento 
estrangeiro. Por fim, se concluirá que tais movimentos ainda se encontram em estágio embrionário e que contam com futuros desafios de incorporação ao sistema regulatório nacional.

\section{ORIGENS DO DEBATE SOBRE QUALIDADE REGULATÓRIA NO BRASIL}

Preliminarmente, importa ressaltar que é possível se identificar três ciclos associados à evolução do debate sobre qualidade regulatória no Brasil. A primeira delas (a ser tratada nesta seção) diz respeito às origens primordiais da discussão sobre o assunto e tem como enfoque as questões relacionadas à motivação da melhoria qualitativa das regulações, ao seu conteúdo e principais ferramentas. Já o segundo ciclo (a ser tratado na próxima seção) tem como núcleo a realização das primeiras experiências (isoladas) voltadas à implementação das ferramentas tidas como instrumentos capazes de melhorar os atos regulatórios. Por último, o terceiro ciclo diz respeito, justamente, ao foco principal deste artigo: o surgimento das tendências de sistematização e coordenação efetiva das melhores práticas em regulação para fortalecimento da qualidade do sistema de regulatório brasileiro ${ }^{7}$.

Consoante com essa linha de raciocínio, a preocupação com a melhora da qualidade das regulações, no Brasil, é uma ideia que, na realidade, surge de fora para dentro. Enquanto, na década de 1980 a literatura nacional se debruçava sobre a necessidade de realização de uma reforma do estado brasileiro, nessa mesma época, a comunidade internacional já se ocupava com a análise de possíveis ferramentais capazes de incrementar a qualidade regulatória dos países (PARKER, 2015, p. 60; OCDE, 2008c). Sob a premissa fundamental de que uma regulação ineficaz e ineficiente pode gerar altos custos desnecessários à iniciativa privada e à sociedade de uma maneira geral, a discussão estrangeira sobre melhora regulatória acabou por se concentrar, principalmente, na Organização para Cooperação e Desenvolvimento Econômico (OCDE) fórum internacional que assumiu papel central na edição de recomendações e diretrizes sobre política regulatória.

Nesse aspecto, já em 1995, a OCDE tratou de editar a "Recomendação sobre a Melhoria da Qualidade da Regulação Governamental", que

\footnotetext{
7 É importante esclarecer que todas essas ondas, em alguma medida, coexistem, uma vez que a literatura nacional ainda procura compreender os fundamentos da melhoria regulatória, ainda procura aperfeiçoar as análises voltadas para eficácia dos instrumentos de melhora regulatória e uma vez que o movimento de coordenação efetiva e sistematização ainda é embrionário.
} 


\section{REVISTA ESTUDOS INSTITUCIONAIS}

JULHO/DEZEMBRO - ISSN 2447-5467

aspirava ser a primeira consolidação internacional de padrões de qualidade regulatória (OCDE, 1995) e que continha uma lista de medidas para a tomada de decisão regulatória (SOUSA, 2012, p. 105). A partir de então, diversos outros documentos foram editados pela organização, no sentido de conscientizar os governos acerca da importância da adoção de medidas (principalmente da análise de impacto regulatório) que visassem ao incremento da qualidade das regulações. Como exemplo, é possível se destacar a edição, em 1997, do "Relatório da OCDE sobre Reforma Regulatória" (OCDE, 1997), em 2002, das "Políticas Regulatórias nos países da OCDE: Do intervencionismo à Governança Regulatória" (OCDE, 2002), em 2005, dos "Princípios Norteadores da OCDE para Qualidade e Performance Regulatória" (OCDE, 2005) e, em 2012, da "Recomendação do Conselho da OCDE sobre Política e Governança Regulatória" (OCDE, 2012).

No contexto nacional, com a evolução e certa maturação das discussões acerca do desenho das entidades reguladoras, aquelas sobre melhoria regulatória ganham centralidade e claros contornos com a criação, em 2007, do Programa de Fortalecimento da Capacidade Institucional para Gestão em Regulação ("PRO-REG"). Inspirado nas orientações estampadas nos documentos estrangeiros relatados acima, o PRO-REG, criado pelo Decreto no 6.062/2007, foi resultado de uma parceria com Banco Interamericano do Desenvolvimento ("BID”) e tinha como tônica a melhoria da qualidade regulatória no âmbito federal, por meio, principalmente do fortalecimento: do sistema regulatório, da coordenação das entidades reguladoras, dos mecanismos de legitimidade e de participação social e da qualidade das regulações em si (BRASIL, 2013). Para consecução de tais objetivos, foram designados comitês responsáveis pela condução dos objetivos do projeto $^{8}$, sendo que a Casa Civil, em razão de suas funções institucionais precípuas, acabou liderando grande parte das ações relacionadas ao programa (SANTOS, 2009, p. 117). Durante a sua vigência ${ }^{9}$, o PRO-REG resultou na elaboração

\footnotetext{
${ }^{8}$ Foi criado um Comitê Gestor, composto pelo Ministério do Planejamento, pela Casa Civil da Presidência da República e pelo Ministério da Fazenda e um Comitê Consultivo, composto por representantes das agências reguladoras federais e dos Ministérios aos quais estão vinculadas, do Ministério da Justiça e do Conselho Administrativo de Defesa Econômica.

${ }^{9}$ Conforme expõe Santos (2009, p. 117), o PRO-REG, embora criado em 2007, teve sua execução iniciada efetivamente em 2008. Conforme publicação da Casa Civil da Presidência da República (Histórico do PRO-REG), de 2008 a maio de 2013, o PROREG teria sido executado em parceria com o BID; a partir de maio de 2013, ele fora executado apenas com recursos do Orçamento Federal e, atualmente, não contaria com orçamento específico em âmbito federal.
} 


\section{COORDENAÇÃO EFETIVA E SiSTEMATIZAÇÃO}

de estudos ligados à regulação ${ }^{10}$, na parceria com diversas entidades (nacionais e internacionais) voltadas para as discussões de incremento da qualidade regulatória e na realização de diversos cursos de capacitação de servidores em melhora regulatória ${ }^{11}$.

Fruto de um movimento internacional, o PRO-REG acabou por, internamente, estimular e colocar em voga toda uma literatura voltada para a discussão das melhores medidas capazes de incrementar qualitativamente as regulações. Nesse campo, há que se dar destaque à Análise de Impacto Regulatório (AIR), instrumento de avaliação empírica e ex ante dos custos e benefícios de uma regulação ${ }^{12}$, que há muito já vinha sendo utilizado, isoladamente, por alguns países, mas que, apenas a partir do movimento internacional concentrado na OCDE, parece ter sido recepcionado como ferramenta fundamental para se melhorar a qualidade das regulamentações (SALGADO; HOLPERIN, 2010). Nesse aspecto, conforme o gráfico abaixo, é notável a curva de crescimento de jurisdições que, a partir dos anos 90, aderiram à AIR como instrumento de melhora regulatória:

Gráfico 1 - Evolução da quantidade de jurisdições da OCDE que adotam AIR

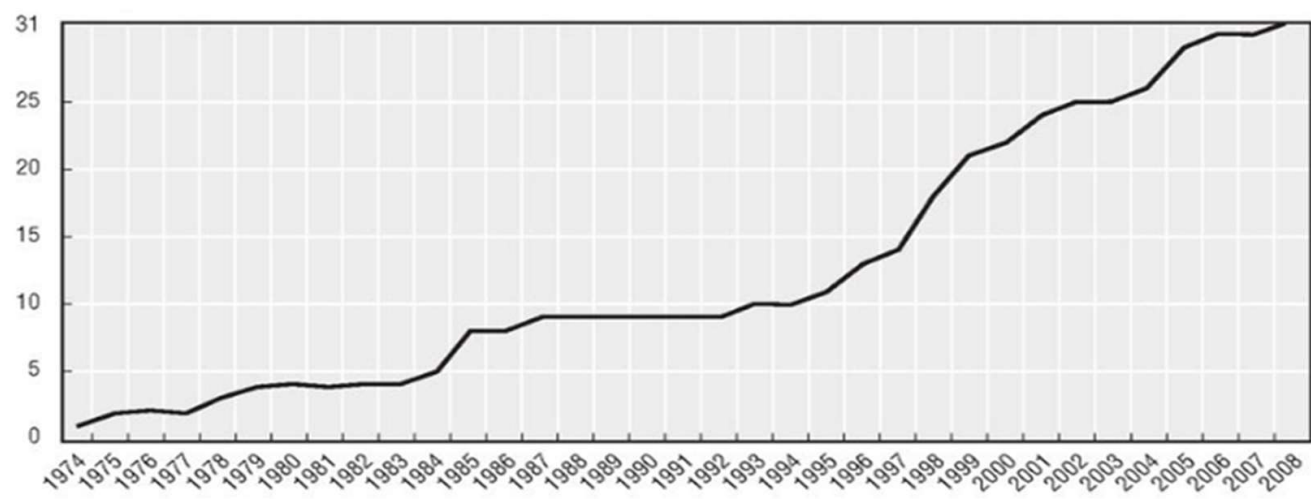

Fonte: Regulatory Impact Analysis, 2009 (OECD)

10 Os estudos elaborados no âmbito do PRO-REG estão disponíveis em: <http://www.casacivil.gov.br/regulacao/documentos/biblioteca>. Acesso em: 10 de out. de 2018.

11 Os cursos de capacitação realizados no âmbito do PRO-REG estão disponíveis em: <http://www.casacivil.gov.br/regulacao/sistema-regulatorio-brasileiro/historico-dopro-reg/capacitacoes-realizadas/capacitacoes-realizadas>. Acesso em: 09 de out. de 2018.

12 Para demais definições da Avaliação de Impacto Regulatório, vide, por exemplo, OCDE (2008) e Blanchet e Bubniak (2017). 


\section{REVISTA ESTUDOS INSTITUCIONAIS}

Além disso, é importante registrar que, não por coincidência, a criação do PRO-REG, entre 2007 e 2008, culmina com o pico de aderência da AIR por diversas jurisdições, conforme mostra o gráfico acima. Tal evidência só corrobora com o argumento de que as discussões de melhora regulatória e de incorporação da AIR ao sistema regulatório brasileiro se iniciam, efetivamente, com o início do programa e como decorrência de um fenômeno exógeno.

Ressalte-se que, consoante o exposto na introdução deste artigo, não se tem como objetivo esgotar as nuances que circunscrevem o debate sobre a adoção, implementação e desenho da AIR no Brasil ${ }^{13}$. Muito embora sejam questões centrais na literatura, limita-se a apenas mencionar seu conteúdo (conforme feito acima) e esclarecer que se trata de uma das ferramentas associadas à melhora da qualidade regulatória. Nesse caso, para fins desta seção, a menção ao instituto do AIR tem por finalidade contextualizar a origem do debate sobre melhora da qualidade regulatória brasileira, que teve início com a criação do PRO-REG: claro resultado de um movimento internacional anterior.

\section{EXPERIÊNCIAS NACIONAIS VOLTADAS PARA O INCREMENTO DA QUALIDADE REGULATÓRIA}

Após a inauguração da preocupação nacional com a melhora regulatória (a partir da criação do PRO-REG), uma série de iniciativas conduzidas, isoladamente, pelas agências reguladoras federais e voltadas para a melhora da qualidade de suas regulações começam a surgir ${ }^{14}$. Além de experiências com AIRs (instrumento que se tornou principal na literatura), as agências também passam a se utilizar de outras ferramentas também tidas como motores do incremento da qualidade regulatória. São elas, conforme Kélvia Albuquerque (2018): a implementação de canais de participação social (e.g., realização de Consultas/Audiências Públicas, além da criação de Ouvidorias), a publicação de Agendas Regulatórias, a elaboração de Gestão de Estoque Regulatório e a realização de Avaliações de Resultado Regulatório (ARRs).

No que se refere às experiências das agências reguladoras federais com AIRs, tem-se que todas já tiveram alguma experiência com o instrumento, inobstante a Agência Nacional Transportes Terrestres (ANTT) tenha sido precursora quanto a elaboração das avaliações

\footnotetext{
13 Para mais sobre o tema, vide Silva (2012).

14 Nesse sentido, vide, por exemplo, Proença (2012) que reúne uma série de artigos voltados a análise de experiências isoladas de agências reguladoras federais com ferramentas voltadas para o incremento qualitativo das suas regulações.
} 
(BRASIL, 2018b). A agência teria iniciado a elaboração de AIRs, logo em 2009, enquanto que as demais teriam iniciado logo em sequência, conforme a figura abaixo:

Figura 1 - Ano de início de elaboração da AIR pelas Agências Federais

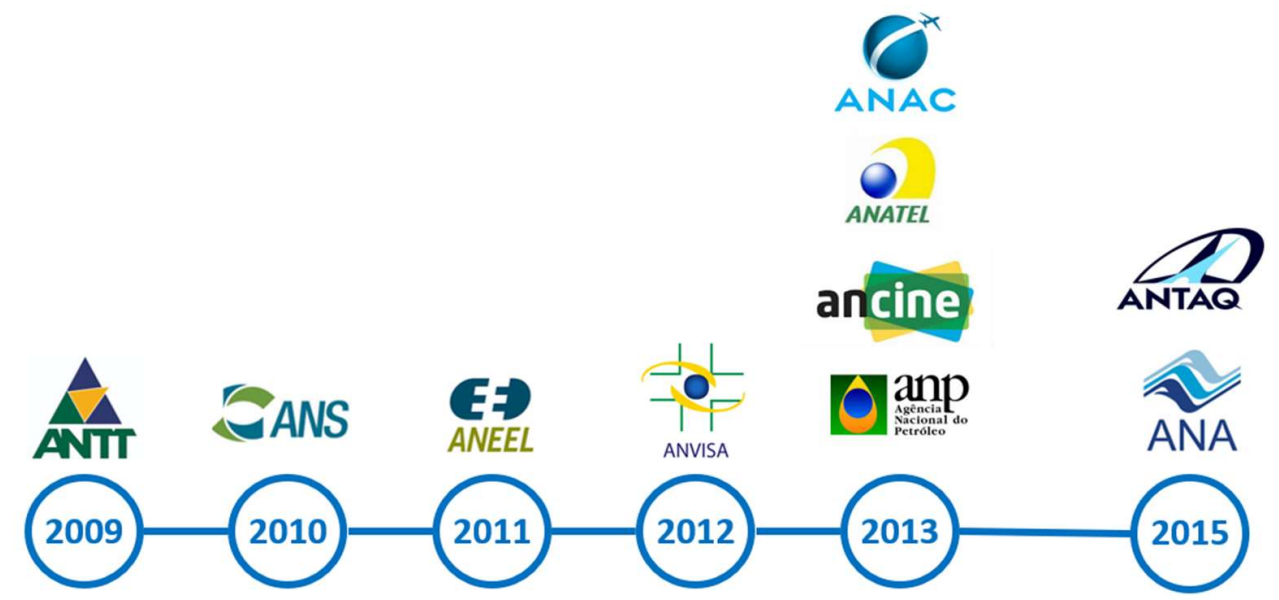

Fonte: Inventário AIR Agências Federais (Casa Civil), 201715

${ }^{15}$ É importante esclarecer que o Inventário AIR Agências Federais foi um levantamento realizado pela Casa Civil da Presidência da República, que comparou os principais elementos de implementação (início de elaboração, quantidade, metodologia, etc.) da AIR pelas agências reguladoras federais. Além disso, é imprescindível ressaltar que houve um esforço metodológico por parte da Casa Civil, no que se refere a quais avaliações realizadas pelas agências poderiam ser efetivamente consideradas como uma AIR para fins de elaboração do levantamento. Nesse aspecto, é possível que haja algum grau de divergência entre o resultado do referido levantamento e os resultados de busca nas plataformas das próprias agências, que podem ter realizado avaliações que consideravam como sendo AIRs propriamente ditas, mas que, para fins do levantamento, não seriam consideradas como tal.

Apenas para ficar com um exemplo, segundo o Inventário, a ANVISA teria iniciado a elaboração de AIR somente a partir do ano de 2012, inobstante o sítio eletrônico da agência destaque que a instituição, em 2008, do Programa de Melhoria do Processo de Regulamentação da ANVISA teria abordado a AIR com determinadas características definidas pela agência (seria um formulário que continha os seguintes campos: descrição do problema; análise dos riscos; objetivos e medidas para alcançar os objetivos; análise de medidas regulatórias alternativas; identificação de impactos para ANVISA, Setor Regulado, Sociedade e Sistema Nacional de Vigilância Sanitária; identificação dos principais atores interessados em conhecer e discutir a proposta; mecanismos de avaliação e monitoramento; documentos de referência; e principais custos e dificuldades com a nova regulamentação ou revisão de um regulamento já existente). Tal divergência parece ter, justamente, fundamento na diferença metodológica de consideração de AIRs efetivas, na medida em que o sítio eletrônico 


\section{REVISTA ESTUDOS INSTITUCIONAIS}

Chama a atenção a falta de homogeneidade quanto aos anos início de elaboração de AIRs pelas agências federais: embora a primeira experiência tenha sido em 2009, grande parte das entidades só veio a ter familiaridade com o instituto anos depois. Aliás, conforme tabela e figura abaixo, tal falta de regularidade também se manifesta em relação ao número de agências em que o uso da AIR já é obrigatório e em que já existe algum tipo de documento normativo sobre o tema, além do que não há homogeneidade quanto a quantidade de vezes em que o instrumento foi utilizado por cada uma das entidades reguladoras:

Tabela 1 - Obrigatoriedade e normatividade do AIR nas Agências Reguladoras Federais

\begin{tabular}{ccc} 
Agência & $\begin{array}{c}\text { AIR } \\
\text { obrigatória }\end{array}$ & $\begin{array}{c}\text { Normativo } \\
\text { sobre AIR }\end{array}$ \\
\hline \hline ANTT & $\mathrm{X}$ & $\mathrm{X}$ \\
\hline ANATEL & $\mathrm{X}$ & $\mathrm{X}$ \\
\hline ANAC & $\mathrm{X}$ & $\mathrm{X}$ \\
\hline ANEEL & $\mathrm{X}$ & $\mathrm{X}$ \\
\hline ANS & $\mathrm{X}$ & $\mathrm{X}$ \\
\hline ANVISA & $\mathrm{X}$ & \\
\hline ANTAQ & & $\mathrm{X}$ \\
\hline ANCINE & & $\mathrm{X}$ \\
\hline ANA & \\
\hline ANP & \\
\hline
\end{tabular}

Fonte: Inventário AIR Agências Federais (Casa Civil), 2017.

da ANVISA também destaca que, somente em 2012 (ano considerado pelo levantamento), a Diretoria Colegiada da Agência teria deliberado sobre o estabelecimento de AIR por níveis de complexidade (AIR nível 1,2 e 3) e tornado a realização de AIR nível 1 obrigatória em determinadas circunstâncias. Nessa época, ainda conforme o sítio eletrônico da ANVISA, "promoveu-se uma melhoria no formulário de AIR 1 anteriormente utilizado, com a criação de um formulário específico para a AIR nível 1 disponível para preenchimento pelas unidades organizacionais da Anvisa, em ambiente WEB, por meio do FormSUS". Note-se ainda que a agência também só disponibiliza as AIRs realizadas a partir de 2012, outra evidência que pode explicar a escolha metodológica da Casa Civil em considerar o ano de início de elaboração de AIR pela ANVISA como sendo o ano de 2012. Disponível em: <http://portal.anvisa.gov.br/analise-de-impacto-regulatorio $>$. Acesso em: 23/10/2018. 
Gráfico 2 - Quantidade de AIRs realizadas pelas Agências Reguladoras Federais (até mar/17) ${ }^{16}$

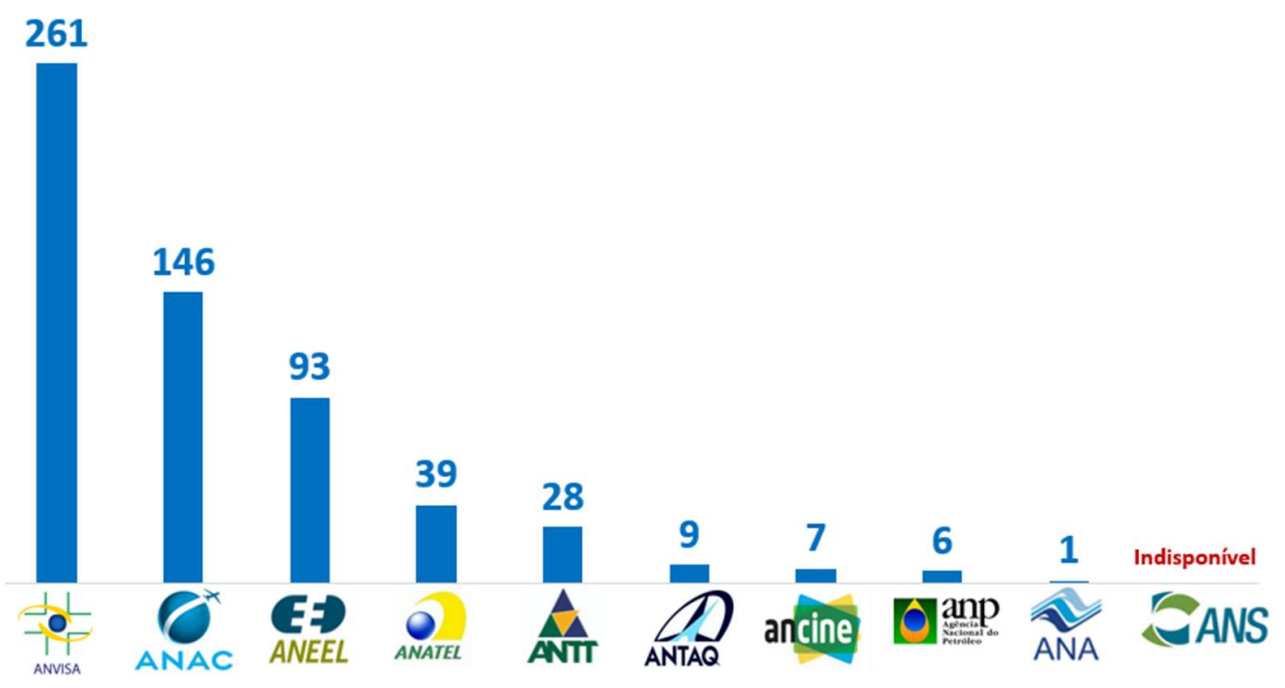

Fonte: Inventário AIR Agências Federais (Casa Civil), 2017.

Aliás, é interessante notar como que o ano de início da elaboração de AIR não tem correlação com a quantidade de vezes que o instituto fora utilizado. Como exemplo, a ANTT, que teria sido pioneira na adoção da ferramenta não figura dentre as agências que mais realizaram AIRs e a ANAC, que só foi adotar a avaliação em 2013, figura como uma das agências que mais se utilizou do instituto.

Ressalta-se, ainda, a falta de uniformidade quanto à metodologia aplicada para realização das AIRs. Conforme recente publicação da Casa Civil da Presidência da República, somente a Agência Nacional de Vigilância Sanitária (ANVISA) previa algum tipo de método específico para elaboração de AIR, enquanto que as demais agências federais não possuiriam uma forma específica de elaboração da avaliação (BRASIL, 2018b).

No que se refere aos mecanismos de participação pública, isto é, formas pelas quais a sociedade consegue participar do processo de tomada de decisão regulatória e fiscalizar a qualidade da atividade regulatória, a literatura já destacou também não haver uma regularidade quanto à presença deles nas leis de criação e decretos regulamentadores das agências reguladoras federais (JUNNIOR, 2013, p. 303-325). Não

${ }^{16}$ Os dados sobre a ANTT (exclusivamente) se referem às AIR elaboradas a partir de 2014. 


\section{REVISTA ESTUDOS INSTITUCIONAIS}

obstante, atualmente, todas elas consagram ao menos alguma das formas de participação social na tomada de decisão e fiscalização regulatória ${ }^{17}$, bem como já contam com processos de realização de consultas públicas e audiências públicas bem estruturados (BRASIL, 2018b).

Em relação à elaboração e publicação de Agendas Regulatórias, é válido ressaltar que se trata de documento, geralmente bianual, que contém os compromissos regulatórios assumidos pelo órgão regulador frente aos regulados. Trata-se de instrumento que possibilita o acompanhamento social das ações das agências reguladoras, bem como que confere maior publicidade, previsibilidade, transparência e eficiência para o processo regulatório ${ }^{18}$. A semelhança das outras ferramentas de melhoria regulatória, também não há homogeneidade quanto à adoção de Agendas Regulatórias pelas agências reguladoras federais. Note-se como não há regularidade quanto aos anos de início de elaboração do referido instituto:

Figura 2 - Ano de início de elaboração da Agendas Regulatórias pelas Agências Federais

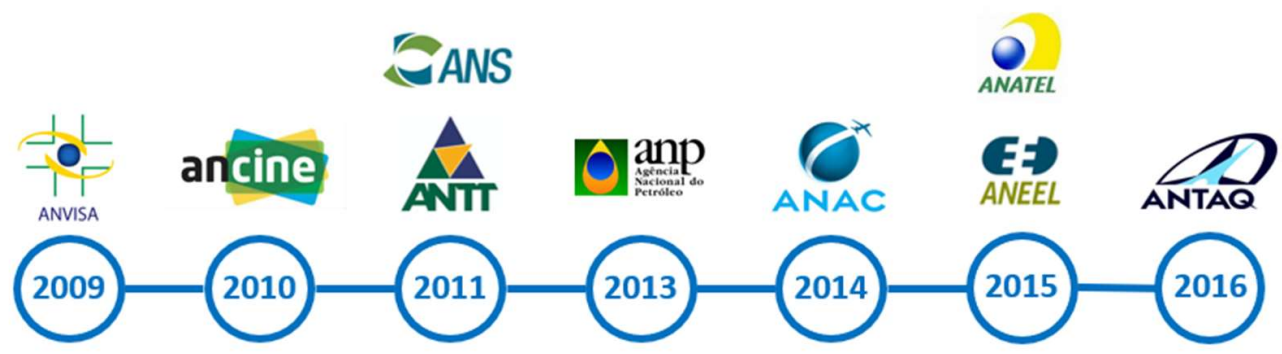

Fonte: Sítio eletrônico das agências reguladoras federais

Por último, quanto à Gestão de Estoque Regulatório e à ARR, importa ressaltar que são instrumentos de análise posterior à edição dos atos normativos. A Gestão (exame periódico dos atos normativos publicados para averiguar a pertinência de sua manutenção, ou necessidade alteração, atualização e revogação) e a ARR (avaliação do desempenho do ato normativo quanto ao efetivo alcance dos objetivos originais) garantem que as regulações permaneçam atualizadas, eficientes e consistentes com objetivos regulatórios pretendidos primordialmente. Especificamente em relação às realizações de Gestão de Estoque

\footnotetext{
17 Fonte: consulta ao sítio eletrônico das agências.

18 Disponível em: <http://www.anatel.gov.br/setorregulado/agenda-regulatoria $>$. Acesso em: 13/10/2018.
} 
Regulatório, documento elaborado, em 2018, pela Casa Civil da Presidência da República evidencia a ausência de isonomia, entre as agências reguladoras federais, acerca da metodologia empregada para a consecução da gestão, da regularidade com que é feita e do momento em que começou a ser elaborada (BRASIL, 2018d). Semelhantemente, em relação à ARR, outro documento elaborado pela Casa Civil também destaca que a grande maioria das agências não prevê utilização específica do instituto (BRASIL, 2018b), assim como publicação da OCDE conclui não haver a utilização sistemática e regular da ARR no contexto brasileiro (OCDE, 2016).

Portanto, em resumo, é possível se concluir que não houve uniformidade, entre as agências reguladoras federais, quanto às suas experiências com instrumentos de melhoria regulatória (AIR, canais de comunicação, Agendas Regulatórias, Gestão de Estoque Regulatório e ARR). Pelo exposto, ao menos até o ano de 2016 e meados do ano 2017, grande parte das experiências das agências eram isoladas e não havia um esforço efetivo de sistematização/uniformização delas coordenado por uma autoridade específica.

\section{TENDÊNCIAS ATUAIS RELACIONADAS À MELHORA DA QUALIDADE REGULATÓRIA NO BRASIL}

De acordo com o apresentado até o momento, o movimento original de melhora da qualidade regulatória no Brasil ( $1^{a}$ onda) evoluiu no sentido da adoção de práticas heterogêneas por parte das principais entidades reguladoras setoriais ( $2^{\underline{a}}$ onda). Não obstante, a realidade evidencia que tal evolução não parece ter sido suficiente para fazer frente a um dos principais objetivos associados à ideia de better regulation e de regulação em si: estimular o aumento do investimento privado, principalmente, em projetos de infraestrutura.

Nesse aspecto, relatório econômico publicado pela OCDE (2018) sobre o Brasil destaca que o investimento geral no país ainda é baixo quando comparado à média daqueles realizados por outros países membros da organização: 


\section{REVISTA ESTUDOS INSTITUCIONAIS}

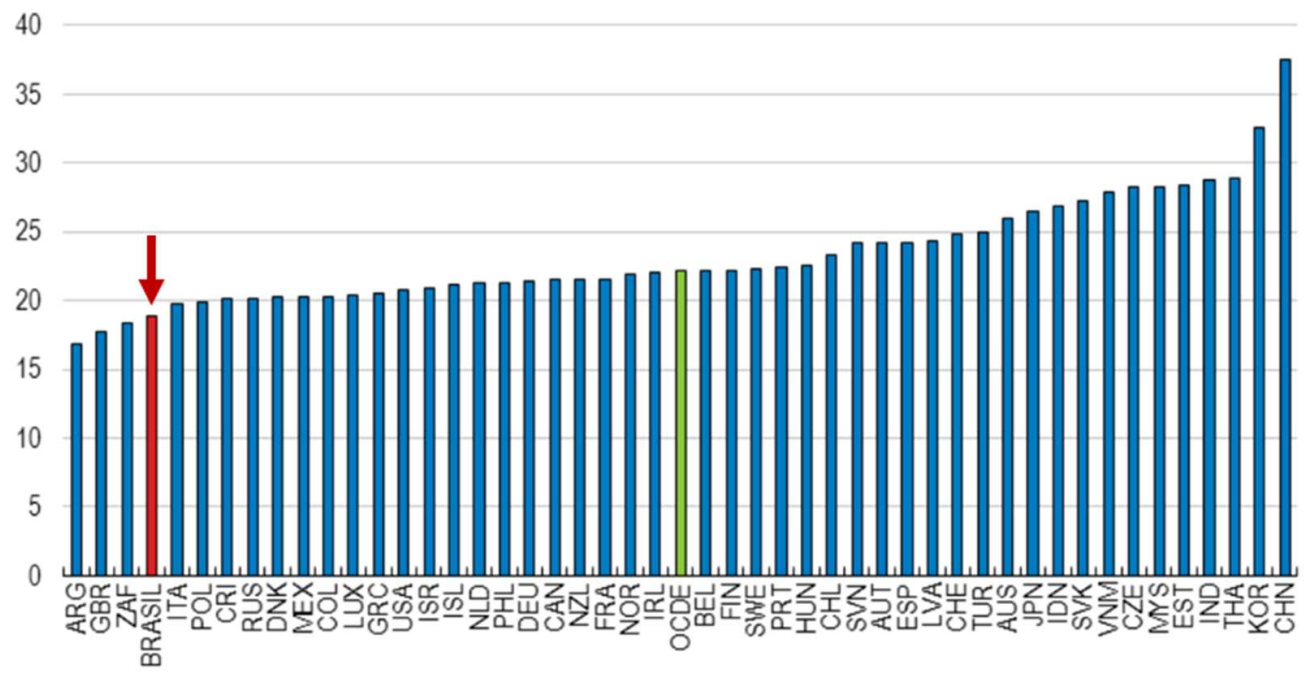

Gráfico 3 - Investimento em \% do PIB (1990 - 2016)

Fonte: Banco de dados Perspectivas Econômicas da OCDE.

No que se refere especificamente à infraestrutura, o mesmo documento também destaca que os investimentos do Brasil, quando comparados aos demais países da américa latina, são baixos (gráfico 4) e, consequentemente, que a qualidade da infraestrutura nacional também é exígua (gráfico 5):

\section{Gráfico 4 - Investimento em infraestrutura em \% do PIB}

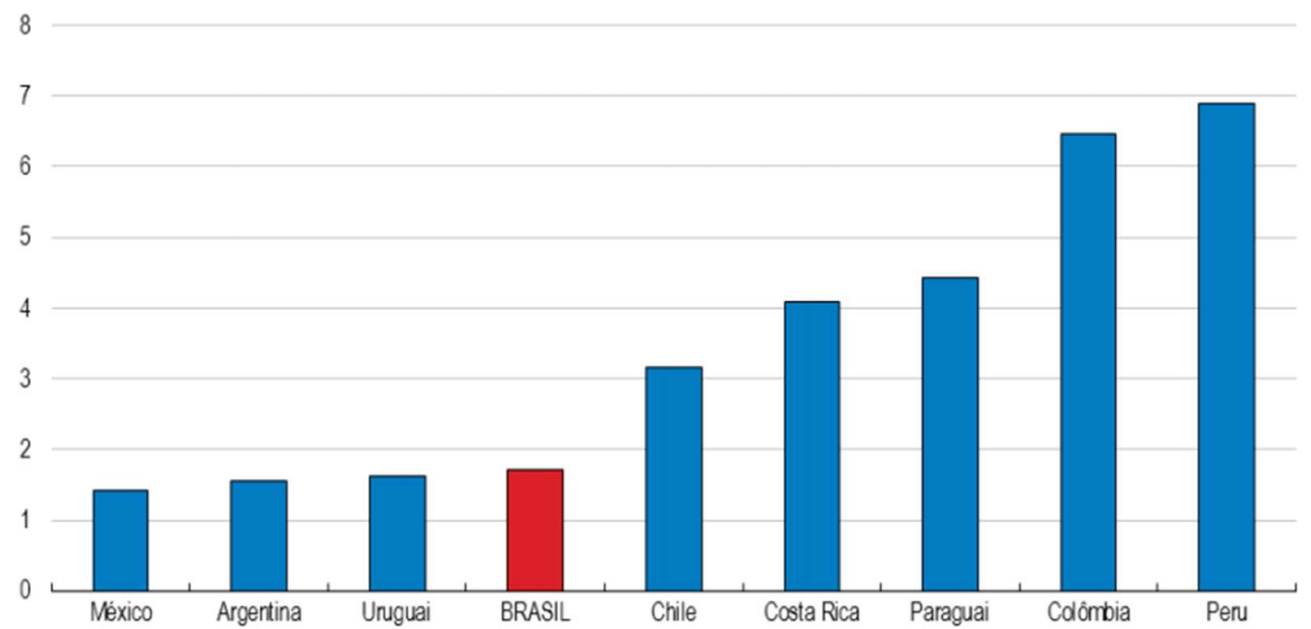

Fonte: Infralatam, BID, CEPAL. 


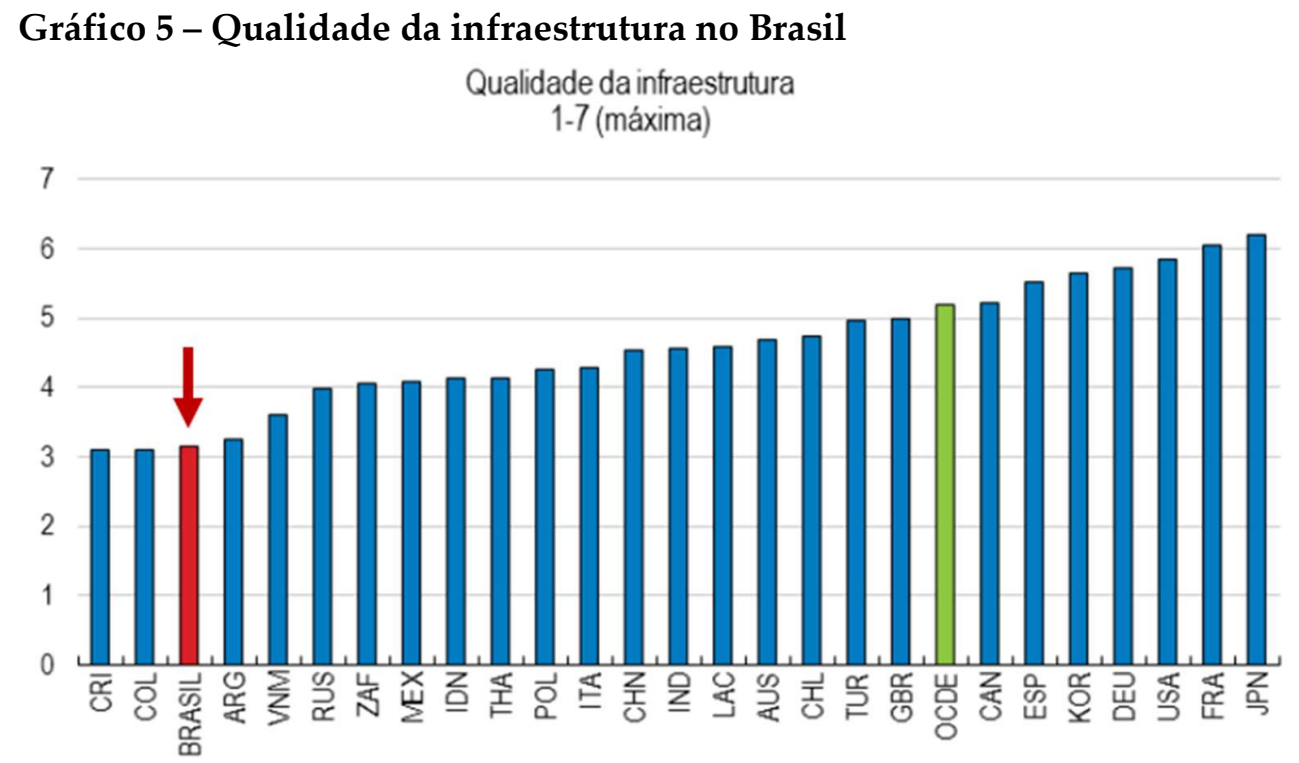

Fonte: Foro Econômico Mundial.

Inevitavelmente, a realidade exposta acima demandaria uma resposta das entidades envolvidas de alguma forma com o sistema regulatório brasileiro. Afinal, se o sistema falhou em seu objetivo precípuo, um novo ciclo teria de ser inaugurado, justamente, com a finalidade de, novamente, estimular $\mathrm{O}$ investimento privado (principalmente estrangeiro) para financiamento de projetos nacionais estruturais.

Tal novo ciclo, além da falta de uniformidade das experiências das agências reguladoras federais com instrumentos de melhora regulatória (conforme exposto mais acima), também deveria ser capaz de lidar com a ausência de uma liderança institucional responsável por comandar de forma organizada todas as iniciativas isoladas das agências ${ }^{19}$. Muito embora reconheça-se que a Casa Civil da Presidência da República viesse assumindo papel de agente coordenador do sistema regulatório nacional,

\footnotetext{
19 Nesse aspecto, diversos países, conforme orientação da OCDE, criaram órgãos de supervisão e coordenação das reformas voltadas para o incremento da qualidade regulatória. Tal movimento resulta da premissa de que a efetiva melhora da qualidade regulatória exige profundo compromisso político com reformas e a criação de órgãos voltados para coordenação e supervisão delas seria uma evidência de demonstração de compromisso com incremento da qualidade da regulação. Sobre esse tema, vide: OCDE (2011, p. 71) e OCDE (2008, p. 78). Aliás, é importante ressaltar que a falta de uma liderança institucional forte e de uniformidade das práticas voltadas para melhora regulatória já eram críticas que permeavam uma parte da literatura. Nesse sentido, vide, por exemplo, Queiroz-Cunha e Delia (2013).
} 


\section{REVISTA ESTUDOS INSTITUCIONAIS}

JULHO/DEZEMBRO - ISSN 2447-5467

quando do início (em 2003) das discussões sobre arranjo institucional das agências ${ }^{20}$, fato é que, na prática, tal coordenação não resultou na adoção sistemática e uniforme das ferramentas de melhora regulatória por parte dos principais atores da regulação nacional.

Diante de todo esse quadro, argumenta-se que a resposta para essas deficiências apontadas foi, justamente, a inauguração de um movimento de sistematização e de efetiva coordenação das melhoras práticas em regulação. Uma série de evidências a serem exploradas, abaixo, sugerem o surgimento desse novo ciclo no debate sobre melhora regulatória no Brasil.

Preliminarmente, é possível se dizer que o fenômeno da sistematização tem tímido início, em 2013, quando algumas das ferramentas de melhora regulatória passaram a ser explicitamente incorporadas no Projeto de Lei Geral das Agências Reguladoras. O projeto de iniciativa parlamentar, que começou a tramitar no Senado em 2013 (PLS 52/2013) e que, atualmente, tramita na Câmara dos Deputados (PL 6621/2016), prevê, por exemplo, a obrigatoriedade de realização de AIR para edição de determinados atos normativos das agências reguladoras federais, a obrigatoriedade de elaboração de Agenda Regulatória e a obrigatoriedade de criação da figura do ouvidor ${ }^{21}$. No mesmo sentido, pode-se dizer que a tramitação do referido projeto também é uma evidência do surgimento do ciclo de coordenação efetiva das melhores práticas em regulação, uma vez que o acompanhamento da tramitação dele é definido como prioridade, em 2018, para a Casa Civil da Presidência da República (ALBUQUERQUE, 2018).

$\mathrm{Na}$ realidade, esses novos processos parecem ter tido início com a criação, em novembro de 2017, pelo Governo Federal, da Política de Governança Pública Federal (Decreto no 9.203/2017)22 no âmbito da administração executiva federal. Dentre outras disposições, essa política

${ }^{20}$ Em 2003, a Casa Civil da Presidência da República coordenou o Grupo de Trabalho Interministerial, que foi instituído para levar a cabo as discussões sobre arranjo institucional das agências reguladoras. Em 2004, tais discussões resultaram na proposição, pelo Poder Executivo, do Projeto de Lei no $3.337 / 04$, que almejava, principalmente, consolidar o formato institucional das agências. Ressalte-se que o referido projeto foi retirado de tramitação, em 2013, pela ex-presidente Dilma Rousseff. Nesse sentido, vide Santos (2009).

21 Nesse sentido, vide os artigos 6o, 21 e 24 do PL 6621/2016. Disponível em: $<$ http://www.camara.gov.br/proposicoesWeb/fichadetramitacao?idProposicao=21200 19>. Acesso em: 14/10/2018.

${ }_{22}$ Concomitantemente, o Governo também elaborou iniciativa de Projeto de Lei acerca da Política de Governança Pública no âmbito federal (Projeto de Lei no 9.163/2017), como forma de dar alcance nacional à política instituída pelo Decreto n⿳0 9.203/2017 
cria, principalmente, o Comitê Interministerial de Governança - a ser coordenado pela Casa Civil ${ }^{23}$ e responsável pela condução da política de governança e de suas vertentes (dentre elas, a melhoria da qualidade regulatória $)^{24}$. Nesse ponto, nota-se que o Governo fora cirúrgico em relação à falta de uma liderança institucional forte para coordenação do sistema regulatório nacional: criou um órgão específico responsável por conduzir iniciativas de melhora regulatória, bem como atrelou sua coordenação à Casa Civil (que já possuía certa experiência nesse sentido). Destaca-se, então, mais uma evidência do nascimento do fenômeno da coordenação efetiva, nos termos do defendido por este artigo.

Além disso, já como resultado da criação da Política de Governança Federal, o Comitê Interministerial de Governança (sob coordenação da Casa Civil), aprovou, em junho deste ano, as Diretrizes Gerais e Roteiro Analítico Sugerido Para Análise De Impacto Regulatório e o Guia Orientativo Para Elaboração De Análise De Impacto Regulatório. Esse movimento mostra clara preocupação do Governo em começar a lidar com a questão da falta de uniformidade da adoção, entre as agências reguladoras federais, dos instrumentos de melhora regulatória. Isso porque tais documentos, que foram frutos de rodadas de discussões coordenadas pela Casa Civil da Presidência da República, objetivam, justamente, sistematizar, no âmbito das agências, a utilização da AIR como ferramenta de melhora regulatória (BRASIL, 2018d) ${ }^{25}$.

23 Nos termos do art. 7º do Decreto no 9.203/2017: “Fica instituído o Comitê Interministerial de Governança - CIG, com a finalidade de assessorar o Presidente da República na condução da política de governança da administração pública federal. Nos termos do art. $8^{\circ}$ do Decreto no 9.203/2017: O CIG será composto pelos seguintes membros titulares: I - Ministro de Estado Chefe da Casa Civil da Presidência da República, que o coordenará; II - Ministro de Estado da Fazenda; III - Ministro de Estado do Planejamento, Desenvolvimento e Gestão; e IV - Ministro de Estado da Transparência e Controladoria-Geral da União".

${ }^{24}$ Nos termos do art. Art. 2º do Decreto 9.203/2017: "Para os efeitos do disposto neste Decreto, considera-se: I - governança pública - conjunto de mecanismos de liderança, estratégia e controle postos em prática para avaliar, direcionar e monitorar a gestão, com vistas à condução de políticas públicas e à prestação de serviços de interesse da sociedade [...]. Além disso, nos termos do art. Art. $3^{o}$ do Decreto 9.203/2017: São princípios da governança pública: I - capacidade de resposta; II - integridade; III confiabilidade; IV - melhoria regulatória; V - prestação de contas e responsabilidade; e VI - transparência".

25 Para elaboração das Diretrizes Gerais e Roteiro Analítico Sugerido Para Análise De Impacto Regulatório e do Guia Orientativo Para Elaboração De Análise De Impacto Regulatório foram coordenadas, pela Casa Civil, reuniões técnicas com as Agências Reguladoras Federais, bem como foi coordenada, pela Casa Civil, consulta pública sobre os documentos. 


\section{REVISTA ESTUDOS INSTITUCIONAIS}

Por fim, ainda na seara da tendência de sistematização da utilização de ferramentas de melhora regulatória, o documento Gestão do Estoque Regulatório: Iniciativas das Agências Reguladoras Federais publicado em maio de 2018 pela Casa Civil também mostra esforço nesse sentido (BRASIL, 2018c). Isso porque a referida publicação contempla uma análise da utilização do instrumento de Gestão de Estoque Regulatório em todas as agências reguladoras federais - uma clara tentativa, coordenada pela Casa Civil, de obter um panorama da utilização do instituto para, possivelmente, a edição de um próximo guia sobre o tema. Novamente, tem-se nova evidência das tendências de coordenação efetiva e de sistematização ${ }^{26}$.

Assim, é possível se concluir que, principalmente, a partir do final do ano de 2017 e ao longo do ano de 2018, diversos acontecimentos (analisados acima) sugerem o surgimento de duas novas tendências relacionadas ao debate sobre melhora da qualidade regulatória no Brasil: as tendências de coordenação efetiva (pela Casa Civil) e sistematização (por meio da edição de normas e de guias) das melhores práticas regulatórias para fortalecimento do sistema de regulação nacional. Como se pode notar também, o nascimento desses fenômenos teve como uma de suas tônicas principais a ainda atual necessidade de captação de investimentos para fazer frente à necessidade de aporte de recursos, principalmente na área de infraestrutura.

\section{CONCLUSÕES}

Em síntese, este artigo procurou argumentar que, atualmente, vigoram duas novas tendências relacionadas ao debate nacional sobre melhora regulatória: as tendências (i) de coordenação efetiva e (ii) de sistematização de boas práticas de regulação. Conforme se expôs, o movimento original de melhora da qualidade regulatória, no Brasil, evoluiu no sentido da adoção de práticas heterogêneas por parte das principais entidades reguladoras setoriais e que não foram suficientes para fazer frente a um dos principais objetivos associados à ideia de better regulation, ou seja, de estimular o aumento do investimento privado, principalmente, em projetos de infraestrutura.

26 Aliás, é válido registrar também, que, como outras evidências do fenômeno de coordenação efetiva, em 2018, a Casa Civil, em parceria com a Escola Nacional de Administração Pública ("ENAP"), tem coordenado a realização de capacitações para disseminação de boas práticas regulatórias. Para acesso à agenda de realizações das capacitações $\quad$ vide: $\quad$ http://www.casacivil.gov.br/conteudo-deregulacao/regulacao/programacao-2018/arquivo-programacao-2018>. Acesso em 14 de out. 2018. 
Após o desenho desse panorama, analisou-se uma série de acontecimentos recentes, que sugeriram o surgimento das tendências de coordenação efetiva e de sistematização de boas práticas de regulação. Nessa averiguação, concluiu-se que as iniciativas das agências reguladoras federais voltadas para melhorar a regulação de certos setores começam a ser, por meio de um efetivo movimento coordenado pela Casa Civil da Presidência da República, sistematizadas em normas e guias orientativos.

Ainda no que diz respeito, a essas tendências é importante registrar que são fenômenos (i) muito recentes e (ii) limitados. Não obstante sejam simples constatações, elas implicam alguns desafios, que a academia e os próprios atores do sistema regulatório brasileiro terão de enfrentar, futuramente, para dar prosseguimento ao incremento qualitativo progressivo das regulações nacionais.

De um lado, ressalta-se que as tendências de sistematização e coordenação efetiva são fenômenos datados, principalmente, no ano de 2017. Nesse sentido, é notória a incipiência dos fenômenos, que, inevitavelmente, faz levantar desafios quanto à sua eficácia pragmática no médio e longo prazo. Como exemplo, é possível se indagar: será que as Diretrizes e o Guia de AIR serão, efetivamente, incorporados por todas as agências reguladoras federais? Quanto tempo essa incorporação pode levar? Até então, há somente adesão explícita aos referidos documentos por parte da ANATEL, que, recentemente, editou manual de boas práticas regulatórias prevendo a realização de AIR, nos temos do Guia publicado pela Casa Civil (BRASIL, 2018a, p. 11).

De outro lado, como é possível de se notar da exposição feita na seção acima, ressalta-se que as tendências de sistematização e coordenação efetiva são fenômenos ocorridos, exclusivamente, na esfera federal e no âmbito do poder executivo. Dessa constatação surgem, de plano, as seguintes perguntas: essas tendências se espalharão para as outras esferas da federação (estados e municípios)? E para o poder Legislativo? Essas indagações refletem desafios associados à possibilidade de replicação desses fenômenos em âmbitos distintos, mas que contemplam atores que também fazem parte do sistema regulatório nacional. Nesse caso, assim como o Governo Federal, os Governos estaduais e municipais também são reguladores e, assim como o Poder Executivo, o Poder Legislativo, por função precípua, também regula ${ }^{27}$.

\footnotetext{
27 À luz dessas observações, já é possível identificar uma literatura preocupada, por exemplo, como o uso abrangente da AIR para todos os tipos de atos normativos (sejam eles de âmbito federal, estadual ou municipal, ou advindos do poder executivo, ou legislativo). Nesse sentido, vide Santos (2009) e Salinas (2016).
} 


\section{REVISTA ESTUDOS INSTITUCIONAIS}

Em consonância com o exposto ao longo deste artigo, como a demanda por investimentos é cíclica, certamente os novos ciclos relacionados à melhora regulatória terão de acontecer e o enfretamento das questões expostas nesta conclusão podem ser bons indícios de quais serão as próximas ondas associadas à necessidade do incremento progressivo da qualidade das regulações no Brasil.

\section{REFERÊNCIAS}

ACCURSO, Jorge S. Dez anos de regulação. In PROENÇA, Jadir Dias; VIEIRA DA COSTA, Patrícia; MONTAGNER, Paula. Desafios da regulação no Brasil. Brasil: ENAP, 2009.

ALBUQUERQUE, Kélvia. Análise de Impacto Regulatório no Brasil. Apresentação na 95a Reunião da Câmara de Saúde Suplementar. Casa Civil. 2018. Disponível em: <http://www.ans.gov.br/images/stories/Interecoes_com_ANS/Apresenta cao_CSS/95_apresentacao_air_brasil.pdf>. Acesso em: 01 de out. de 2018.

BLANCHET, Luiz Alberto; BUBNIAK Priscila Lais Ton. Análise de Impacto Regulatório: uma ferramenta e um procedimento para a melhoria da regulação. Revista Pensar, Fortaleza, v. 22, n. 3, p. 1-15, 2017.

BRASIL. Agência Nacional de Telecomunicações. Manual de Boas Práticas Regulatórias. 2018 (2018a). Disponível em: $<$ http://www.casacivil.gov.br/regulacao/boas-praticasregulatorias/manual-de-boas-praticas-regulatorias/manualbpranatel.pdf $>$. Acesso em: 14 de out. de 2018.

BRASIL. Casa Civil da Presidência da República. Histórico do PRO-REG. Publicado em 14/10/2013 (2013). Disponível em: $<$ http://www.casacivil.gov.br/regulacao/sistema-regulatoriobrasileiro/historico-do-pro-reg/historico-do-pro-reg-pagina>. Acesso em: 01 de out. de 2018. 
BRASIL. Casa Civil da Presidência da República. Inventário AIR - Visão Geral da Análise de Impacto Regulatório nas Agências Reguladoras Federais. Publicado em 20 de jun. de 2018 (2018b). Disponível em: $<$ http://www.casacivil.gov.br/regulacao/apresentacao-regulacaopasta/acesse-aqui/inventario-air-visao-geral-da-analise-de-impactoregulatorio-nas-agencias-reguladoras-federais/inventario-air-visaogeral-da-analise-de-impacto-regulatorio-nas-agencias-reguladorasfederais>. Acesso em: 10 de out. de 2018.

BRASIL. Casa Civil da Presidência da República. Gestão do Estoque Regulatório Iniciativas das Agências Reguladoras Federais. 2018 (2018c).

$<$ http://www.casacivil.gov.br/regulacao/apresentacao-regulacaopasta/acesse-aqui/gestao-estoque-regulatorio/gestaoestoqueregulatorioiniciativasagenciasreguladorasfederais.pdf>. Acesso em: 10 de out. 2018.

BRASIL. Casa Civil da Presidência da República. Diretrizes gerais e guia orientativo para elaboração de Análise de Impacto Regulatório - AIR. Brasília: Presidência da República, 2018 (2018d).

COSTA, Frederico Lustosa da. Brasil: 200 anos de Estado; 200 anos de administração pública; 200 anos de reformas. RAP, Rio de Janeiro, v. 42, n. 5, p. 829-874, 2008.

GAETANI, Francisco; Albuquerque, KÉLVIA. Análise de impacto regulatório e melhoria regulatória. In RAMALHO, Pedro Ivo Sebba. Regulação e Agências Reguladoras Governança e Análise de Impacto Regulatório. Brasília: Anvisa, 2009.

JÚNIOR, Antonio Eduardo de Albuquerque. As Agências Reguladoras Federais e os Canais de Controle e Participação da Sociedade. Revista Gestão E Sociedade, v. 7, n. 18, p. 303-325, 2013. 


\section{REVISTA ESTUDOS INSTITUCIONAIS}

JULHO/DEZEMBRO - ISSN 2447-5467

OCDE (ORGANISATION FOR ECONOMIC COOPERATION AND DEVELOPMENT). Building an institutional framework for regulatory impact analysis. Version 1.1 Regulatory Policy Division Directorate for Public Governance and Territorial Development. Paris, 2008 (2008a).

OCDE. Government Capacity to Assure High Quality Regulation in Brazil. Paris, 2008 (2008b).

OCDE. Indicators of Regulatory Policy and Governance Latin America 2016 Brazil. 2016. Disponível em: <http://www.oecd.org/gov/regulatorypolicy/Brazil-regulatory-policy-ireg-2016.pdf >. Acesso em 12/10/2018.

OCDE. OECD Guiding Principles for Regulatory Quality and Performance. Paris, 2005.

OCDE. OECD Reviews of Regulatory Reform Brazil Strengthening Governance for Growth. Paris, 2008 (2008c).

OCDE. Recommendation of the Council of the OECD on Improving the Quality of Government Regulation. Paris, 1995.

OCDE. Recommendation of the Council of the OECD on Regulatory Policy and Governance. Paris, 2012.

OCDE. Regulatory Policies in OECD Countries from Interventionism to Regulatory Governance. Paris, 2002.

OCDE. Regulatory Policy and Governance: Supporting Economic Growth and Serving the Public Interest, 2011.

OCDE. The OECD Report on Regulatory Reform: Synthesis, Paris, 1997.

OCDE. Relatórios Econômicos OCDE - BRASIL 2018. Construindo um Brasil mais próspero e mais produtivo. Brasília, 2018. Disponível em: 
$<$ http://www.oecd.org/eco/surveys/Construindo-um-Brasil-maisprospero-e-mais-produtivo-OCDE-relatorios-economicos-2018.pdf $>$. Acesso em: 14 de out. de 2018.

PARKER, David. Formulação de Políticas Baseada em Evidências. In SALGADO, Lucia Helena; FIUSA, Eduardo P.S. Marcos regulatórios no Brasil: aperfeiçoando a qualidade regulatória. Rio de Janeiro: Ipea, 2015.

PROENÇA, Jadir Dias; Paulo, Carla Beatriz de. Experiências Exitosas em Regulação na América Latina e Caribe. Brasília: Presidência da República, 2012.

QUEIROZ-CUNHA, Bruno; DELIA, Rodrigo. Assessing Regulatory Governance and Patterns of Regulatory Reform in Brazil. Osservatorio sull'Analisi di Impatto della Regolazione. 2013.

RAGAZZO, Carlos Emmanuel Joppert. Regulação jurídica, racionalidade econômica e saneamento básico. Rio de Janeiro: Renovar, 2011.

RAMALHO, Pedro Ivo Sebba. Regulação e agências reguladoras: reforma regulatória da década de 1990 e desenho institucional das agências no Brasil. In RAMALHO, Pedro Ivo Sebba. Regulação e Agências Reguladoras Governança e Análise de Impacto Regulatório. Brasília: Anvisa, 2009.

SALGADO, Lucia Helena; HOLPERIN, Michelle Moretzsohn. Análise de impacto-ferramenta e processo de aperfeiçoamento da regulação. Radar n. 8, Ipea, 2010.

SALINAS, Natasha Schmitt Caccia. Por um Uso Abrangente da Análise de Impacto Regulatório no Brasil. Coluna Direito do Estado. № 126, 2016. Disponível em: $<$ http://www.direitodoestado.com.br/colunistas/natasha- 


\section{REVISTA ESTUDOS INSTITUCIONAIS}

salinas/por-um-uso-abrangente-da-analise-de-impacto-regulatorio-nobrasil>. Acesso em: 14 de out. de 2018.

SANTOS, Luiz Alberto dos. Desafios da governança regulatória no Brasil. In PROENÇA, Jadir Dias; VIEIRA DA COSTA, Patrícia; MONTAGNER, Paula. Desafios da regulação no Brasil. Brasil: ENAP, 2009.

SANTOS, Luiz Alberto dos. Desafios da governança regulatória no Brasil. In RAMALHO, Pedro Ivo Sebba. Regulação e Agências Reguladoras Governança e Análise de Impacto Regulatório. Brasília: Anvisa, 2009.

SILVA, Danielle Assafin Vieira Souza; FONSECA, Marcus Vinícius de Araujo. Monitoramento para avaliação do desempenho regulatório do Instituto Nacional de Metrologia, Qualidade e Tecnologia. Rev. Adm. Pública, Rio de Janeiro, v. 49, n. 2, p. 447-472, 2015.

SILVA, Gustavo Henrique Trindade da. A Análise De Impacto Regulatório Na Anvisa: Uma Estratégia De Governança E Melhoria Da Qualidade Regulatória. In PROENÇA, Jadir Dias; Paulo, Carla Beatriz de. Experiências Exitosas em Regulação na Ameríca Latina e Caribe. Brasília: Presidência da República, 2012.

SOUSA, Renan Martins de. A Análise de Impacto Regulatório (AIR) e o papel do Tribunal de Contas da União na avaliação da regulação setorial. Revista do TCU, v. 123, 2012. 